\title{
Black Widow Spider Envenomation with Elevated Troponin I Levels
}

\author{
Murat Daş, Okhan Akdur, Canan Akman, Yasemin Çetinkaya \\ Department of Emergency Medicine, Çanakkale Onsekiz Mart University, Çanakkale, Turkey
}

Cite this article as: Daş M, Akdur O, Akman C, Çetinkaya Y. Black Widow Spider Envenomation with Elevated Troponin I Levels. J Emerg Med Case Rep 2018; 9: 55-7.

\begin{abstract}
Introduction: The black widow spider is found worldwide. Alpha-latrotoxin is responsible for the toxic effects related to the spider bite. We report the case of a patient who presented at the emergency department after being bitten by a black widow spider that later developed increased cardiac enzymes.

Case Report: The patient was a 24-year-old male who had been bitten by a black spider inside his shoe while he was working in the garden. The patient was referred to the emergency department of department of emergency medicine Çanakkale Onsekiz Mart University Faculty of Training and Research Hospital with nausea, vomiting, and severe rigidity in the abdomen for the differential diagnosis of acute abdomen. With severe sweating, the patient had rales in the lower lung zones, and abdominal examination revealed diffuse abdominal guarding. Blood biochemistry revealed creatine kinase (CK): $1838 \mathrm{U} / \mathrm{L}, \mathrm{CKMb}: 71.6 \mathrm{U} / \mathrm{L}$, and troponin I: $0.14 \mathrm{ng} / \mathrm{mL}$. In follow-ups, the troponin I levels increased to $3.01 \mathrm{ng} / \mathrm{mL}$. Electrocardiography revealed normal sinus rhythm. He was followed with a bedside monitor for 3 days in the emergency department. When the patient's troponin I and CK levels decreased, at the end of the third day he was discharged.
\end{abstract}

Conclusion: Black widow envenomation should be followed for cardiac toxicity other than symptoms, such as muscle spasms, sweating, anxiety, and headache.

Keywords: Black widow spider, troponin, envenomation

Received: 28.10.2017 Accepted: 19.12.2017

\section{Introduction}

The black widow spider is found worldwide. Although it is mostly known by its name "the black widow," it can also be brown or red. The female black widow spiders are three times larger than the males. Alpha-latrotoxin is responsible for the toxic effects related to the spider bite. In the human body, this toxin induces the massive release of neurotransmitters, such as acetylcholine and norepinephrine, from nerve endings that leads to the clinical picture called "latrodectism." Following the sensation of a needle prick at the bite site locally, pain and numbing develop that radiate to the bitten limb. Hypertension and tachycardia are often observed. Among systemic symptoms, muscle cramps, nausea, vomiting, sweating, and headache are common. Atrial fibrillation, myocarditis, priapism, or death rarely occur (1). Through this case, we report the case of a patient who presented at the emergency department after being bitten by a black widow spider that later developed increased cardiac enzymes. This report has been written with the patient's consent.

\section{Case Report}

The history of previously healthy 24-year-old male patient revealed that he had been bitten by a black spider inside his shoe while he was working in the garden. Initially, he neglected it and continued working, but soon he felt burning sensation and 
severe pain spreading up his left leg. He visited a hospital when this pain radiated toward his groin and abdomen. After a preliminary evaluation in an external center, he was referred to the emergency department of our hospital for the differential diagnosis of acute abdomen with nausea, vomiting, and severe rigidity in the abdomen. In the emergency service, blood pressure was 140/65 mmHg, pulse was $95 / \mathrm{min}$, respiratory rate was $17 / \mathrm{min}$, oxygen saturation in room air was $94 \%$, body temperature was $36.7^{\circ} \mathrm{C}$, and blood glucose level was 154 mg/dL. His general condition was moderate. He was conscious, oriented, and cooperative, but he appeared anxious and was sweating. An ecchymosis with a diameter of $0.5 \mathrm{~cm}$ was visible between the first and second metatarsal bones of the left foot

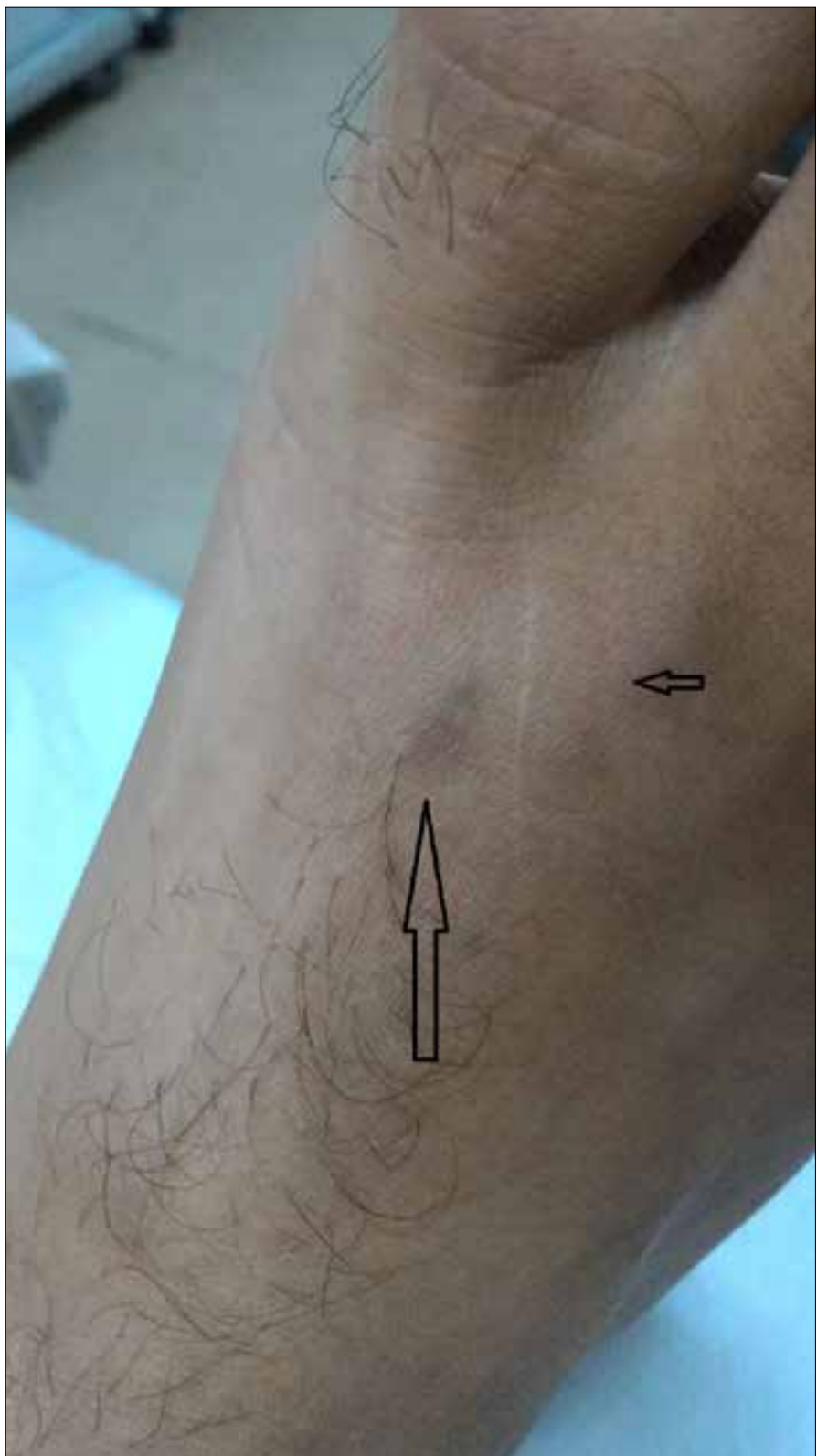

FIGURE 1. The dorsal area of the patient's left foot. The thick arrow points to the ecchymotic area of the size of $05 \times 05 \mathrm{~cm}$ at the bite site; the thin arrow points to the halo-like erythematous area surrounding the bite site.
(Figure 1). With severe sweating, the patient had rales in the lower lung zones, and abdominal examination revealed diffuse abdominal guarding and muscle rigidity. He complained of muscle spasms in both upper and lower limbs. The hemogram revealed white blood cell: 18850/mL, hemoglobin: 16.25 mg/dL, platelet count: 293,000; blood biochemistry revealed creatine kinase (CK): $1838 \mathrm{U} / \mathrm{L}, \mathrm{CKMb}$ : $71.6 \mathrm{U} / \mathrm{L}$, potassium: $6.32 \mathrm{mmol} / \mathrm{L}$, and troponin l: $0.14 \mathrm{ng} / \mathrm{mL}$ (normal range: $0.1-0.3 \mathrm{ng} / \mathrm{mL}$ and troponin I). Venous blood gases were identified as $\mathrm{pH}$ : 7.28, $\mathrm{PCO}_{2}$ : 49.2, $\left[\mathrm{HCO}_{3}{ }^{-}\right]$: 17.5 , and lactate: 4.5 $\mathrm{mmol} / \mathrm{L}$. In follow-ups, the troponin I levels increased to $3.01 \mathrm{ng} /$ $\mathrm{mL}$, the blood pressure to $200 / 120 \mathrm{mmHg}$, and the pulse rate to 120 per min. Electrocardiography revealed normal sinus rhythm. The patient was consulted with the cardiology department, and a bedside echocardiography (Vivid-e, GE, USA) was performed. It was stated that there were no wall motion defects and that the ejection fraction was within normal ranges. The patient was delivered an infusion of $100 \mu \mathrm{g}$ fentanyl in $100 \mathrm{~mL}$ of isotonic saline to diffuse pain. The patient responded well to analgesia, and the pain gradually diminished. For the hypertension, an infusion of $10 \mathrm{mg}$ nitroglycerin was added to $100 \mathrm{~mL}$ of isotonic saline and delivered at a rate of $10 \mu \mathrm{g} /$ min. Based on the response of the blood pressure, it was increased to a rate of $50 \mu \mathrm{g} / \mathrm{min}$. The patient who had severe anxiety, tachycardia, muscle spasms, and hypertension was delivered an infusion of $10 \mathrm{mg}$ diazepam in $100 \mathrm{~mL}$ of isotonic saline to reduce sympathetic system activation. Because sweating did not subside, a midazolam infusion was delivered at a rate of $1 \mathrm{mg} / \mathrm{h}$. The patient had high CK levels, and was hence delivered $4000-4500 \mathrm{~mL}$ of intravenous fluids daily for rhabdomyolysis. The spider antivenin (correct) was not available for the patient. He was followed with a monitor for 3 days in the emergency service. Once the patient's troponin I and CK levels decreased, metabolic acidosis in blood gases receded, sweating disappeared, and body pains subsided, and the patient was discharged with a scheduled follow-up.

\section{Discussion}

The black widow spiders that have a worldwide geographical distribution can penetrate human skin and lead to envenomation. The black widow spider might sting (bite) people in a variety of settings and at many areas of the body. In their study, Cruz et al. (2) identified the shoe as the rarest bite setting (4.3\%). In the study conducted by Clark et al. (3), the lower limb was identified as the most common bite site, and the head and neck as the rarest. In this case, a black widow spider that entered the shoe of our patient while working in a field lead to envenomation by biting the dorsal portion of the foot.

After a black widow spider bite, a sensation similar to that of a needle prick, pain, and local burning may develop at the bite site. Local swelling and a halo-like erythema surrounding it can be observed at the bite site (4). In our patient, an erythema was observed around the bite site on the dorsum of the foot, but no swelling developed.

The symptoms of systemic toxicity that are known as latrodectism include muscle cramps, hypertension, tachycardia, nausea, vomiting, and headache. These findings usually develop within an hour after the bite, but in some cases this can be prolonged (4-5). The 
presence of severe abdominal pain, muscle contraction and spasm, and severe sweating in our case is similar to that in cases presented in the literature.

Clark et al. (3) classified spider bites in three grades in their series of 163 cases. Based on this, patients with local pain at the bite site and normal vital findings are designated as grade 1. Patients with pain in the muscles of the limb that has been bitten, pain in the abdomen in lower limb bites or pain in the chest with extension in upper limb bites, and local sweating in the bite site or extremity is designated as grade 2 . Finally, patients with generalized muscle pain in the abdomen and chest, generalized sweating, abnormal vital findings [hypertension (systolic blood pressure $>140 \mathrm{mmHg}$ or diastolic blood pressure >90 $\mathrm{mmHg}$ ) and tachycardia (pulse >100/min)], nausea, vomiting, and headache are designated as grade 3 . Based on this grading system, our patient has a grade 3 envenomation clinic as he had generalized muscle pain and sweating, a blood pressure of 200/120 mmHg, and complaints of nausea and vomiting.

Moreover, in the study that reviews a series of 163 cases, laboratory tests were performed for 54 patients with severe clinical picture. Among these patients, 14 had leukocytosis, 7 had elevated CK levels, and 4 had elevated lactate dehydrogenase (LDH) levels (3). The laboratory results of our patient revealed leukocytosis, and while the CK level was high, the LDH level was identified as normal.

In the literature, it has been stated that myocarditis, cardiomyopathy, and elevated troponin levels may be observed following black widow envenomation, and that these might be accompanied by pericardial effusion and cardiogenic edema on a case-to-case basis (5-10). The pathology of the cardiac effects related to the envenomation remain unknown for certain. It is believed that cardiac effects are induced by the activation of the adrenergic system by latrotoxin, the most dominant component of the venom $(5,10)$. Inflammatory cell infiltrates and cytokine activation cause elevated troponin I levels that leads to myocarditis (11). The troponin I levels increased up to $3.01 \mathrm{ng} / \mathrm{mL}$ in the follow-ups of our patient. There are many diseases, including myocardial infarction, pulmonary embolism, myocarditis, and aortic dissection cerebrovascular disease, that increase troponin I levels. However, except sinus tachycardia, no electrocardiography or echocardiography abnormalities were detected.

The treatment of black widow spider envenomation involves local wound care, symptomatic treatment that includes benzodiazepine and opioids, and the delivery of the toxin's antidote antivenin to patients that present with systemic findings (8). It has been reported that patients with hypertension, tachycardia, sweating, nausea, and vomiting caused by adrenergic activity induced by alpha-latrotoxin respond well to benzodiazepine treatment. Besides this, case presentations have reported that the administration of opioid analgesics also yields good results for muscle cramps $(4-6,7,9)$. In our case, to manage the symptoms and findings of severe muscle cramps and pain, nausea, hypertension, tachycardia, and sweating, benzodiazepine and opioids were administered, and at the end of day 3 , the symptoms and impaired laboratory findings had receded. Addition- ally, the CK elevation we attributed to muscle spasms was treated with intravenous fluid replacement.

\section{Conclusion}

Hypertension, tachycardia, nausea, vomiting, headache, and muscle cramps should raise suspicion for systemic involvement. In such patients, cardiac markers and ECG series should be monitored for the findings of cardiac toxicity. The management of patients with generalized muscle spasms, cramps, or rigidity in their body could be performed by closely following the CK levels, administering benzodiazepine and opioids, and aggressive fluid treatment.

Informed Consent: Written consent was obtained from the patient who participated in this study.

Peer-review: Externally peer-reviewed.

Author Contributions: Concept - M.D., O.A.; Design - M.D., O.A.; Supervision - M.D., O.A., Y.Ç.; Resources - M.D., O.A., Y.Ç.; Materials - M.D., Y.Ç.; Data Collection and/or Processing - M.D., Y.Ç.; Analysis and/or Interpretation - M.D.; Literature Search - M.D.; Writing Manuscript - M.D., O.A.; Critical Review - M.D, O.A.; Other -M.D., O.A., C.A.

Conflict of Interest: The authors have no conflict of interest to declare.

Financial Disclosure: The authors declared that this study has received no financial support.

\section{References}

1. Aaron Schneir, Richard F. Clark. Bites and Stings. In: Tintinalli JE, Stapczynski JS, Ma JO editors. Tintinalli's emergency medicine a comprehensive study guide. 8nd ed. New York: McGraw-Hill; 2016. p. 1371-9.

2. Sotelo Cruz N, Gómez Rivera N. Neurotoxic manifestations of black widow spider envenomation in paediatric patients. Neurologia 2016; 31: 215-22. [CrossRef]

3. Clark RF, Wethern-Kestner S, Vance MV, Gerkin R. Clinical presentation and treatment of black widow spider envenomation: a review of 163 cases. Ann Emerg Med 1992; 21: 782-7. [CrossRef]

4. Camp NE. Black widow spider envenomation. J Emerg Nurs 2014; 40: 193-4. [CrossRef]

5. Golcuk $Y$, Velibey $Y$, Gonullu H, Sahin M, Kocabas E. Acute toxic fulminant myocarditis after a black widow spider envenomation: case report and literature review. Clin Toxicol (Phila) 2013; 51: 191-2. [CrossRef]

6. Boyer LV, Binford GJ, Degan JA. Spider bites. In Auerbach PS, ed.: Wilderness medicine, 6th ed. Philadelphia: Elsevier; 2011: 993-5.

7. Erdur B, Turkcuer I, Bukiran A, Kuru O, Varol I. Uncommon cardiovascular manifestations after Latrodectus bite. Am J Emerg Med 2007; 25: 232-5. [CrossRef]

8. Kose A, Bozkurt S, Lok U, Zengmol M, Yildirim C, Gunay N, et al. Presumptive Latrodectus bite with ileus and myocardial involvement. Wilderness Environ Med 2010; 21:271-2. [CrossRef]

9. Levine M, Canning J, Chase R, Ruha AM. Cardiomyopathy following Latrodectus envenomation. West J Emerg Med 2010; 11:521-3.

10. Sari I, Zengin S, Davutoglu V, Yildirim C, Gunay N. Myocarditis after black widow spider envenomation. Am J Emerg Med 2008;26: 630.e1-3. [CrossRef]

11. Bush SP, Davy JV. Troponin elevation after black widow spider envenomation. CJEM 2015; 17: 571-5. [CrossRef] 